\title{
Clinical Evaluation of 188 Patients with Contracted Socket
}

Didem Serin ${ }^{1}$, Şafak Karslıoğlu ${ }^{2}$, Müslime Akbaba ${ }^{2}$, İbrahim Bülent Buttanrı ${ }^{1^{*}}$ and Korhan Fazıl ${ }^{2}$

${ }^{1}$ Haydarpaşa Numune Education and Research Hospital, 2nd Eye Clinic, Istanbul, Turkey

${ }^{2}$ Istanbul Oculoplastics, Oculoplastic Surgery and Ocular Oncology Center, Istanbul, Turkey

"Corresponding author: Ibrahim Bulent Buttanri, Haydarpasa Numune Trainig and Research Hospital, 2nd Eye Clinic, Caddesi No: 40 Uskudar/lstanbul Istanbul, Turkey, Tel: 900505 5792566, Fax: 90216 3377877; E-mail: bulent_but@yahoo.com

Rec date: Jul 29, 2014; Acc date: Aug 23, 2014; Pub date: Aug 25, 2014

Copyright: ( 2014 Serin D, et al. This is an open-access article distributed under the terms of the Creative Commons Attribution License, which permits unrestricted use, distribution, and reproduction in any medium, provided the original author and source are credited.

\begin{abstract}
Purpose: To evaluate our results in the management of socket contraction.

Design: Case series

Method: One hundred and eighty eight patients with contracted sockets were retrospectively analyzed. Reasons for eye removal, type of initial surgery, presence of an implant, time of onset of contraction, degree of contraction, additional pathologies accompanying contraction, type of surgery for the contracted socket, additional interventions, number of surgeries, and final status were recorded and evaluated.
\end{abstract}

Results: There were 101 (53.72\%) male and 87 (46.28\%) female patients, with an age range between 1 and 78 years (mean 35.46 years). Mean follow-up was $45.6 \pm 22.34$ months (range $5-120$ months). Trauma was the reason for eye removal in $80(42.55 \%)$ patients. Enucleation performed in $146(77.66 \%)$ patients was the most common initial surgery. An implant was absent in 143(76.06 \%) patients. Time of onset of contraction was longer than 5 years in 56 $(29.79 \%)$ patients. Moderate or severe contraction was recorded in $134(71.28 \%)$ patients. Totally 229 procedures were performed for socket surface expansion and $30.32 \%$ of patients required more than one surgery. $151(80.32 \%)$ patients had additional pathologies. At the final visit, $138(73.4 \%)$ patients had a good or acceptable result.

Conclusion: Contracted socket remains to be a challenging entity of oculoplastic surgery. It may develop at any time following removal of the eye. Additional pathologies frequently accompany the contracted socket. Even though wearing an artificial eye eventually becomes possible in the majority of cases, it is still hard for some patients even after a series of reconstructive interventions.

Keywords: Contracted socket, Socket surgery, Anophthalmia

\section{Introduction}

Anopthalmia leads to cosmetic deformity and may affect patients' psychology [1]. Fitting an ocular prosthesis is mandotary in the management of anophthalmia. Socket contraction is the main problem in the anopthalmic patients and characterized by scarring, granulation tissue formation and loss of fornices [2]. Histopathological changes are infiltration of inflammatory cells, metaplasia of conjunctival epithelial cells, keratinization and goblet cell count reduction [3]. The aim of socket surgery is to form a socket which is able to carry an ocular prosthesis which simulates normal fellow eye [4,5]. In an anophthalmic socket, to fit prosthesis, presence of adequate fornices and lining is mandatory. Socket contraction leads to fornix and lining deficiency (Figure 1). Many factors, including fibrosis due to initial trauma, poor surgical technique, multiple socket procedures, irradiation, alkali burns, cicatrizing disease of conjunctiva may be the reason of socket contraction [6]. In moderate or severe forms of socket contraction, it may be impossible to fit prosthesis (Figures 2-4) [7].

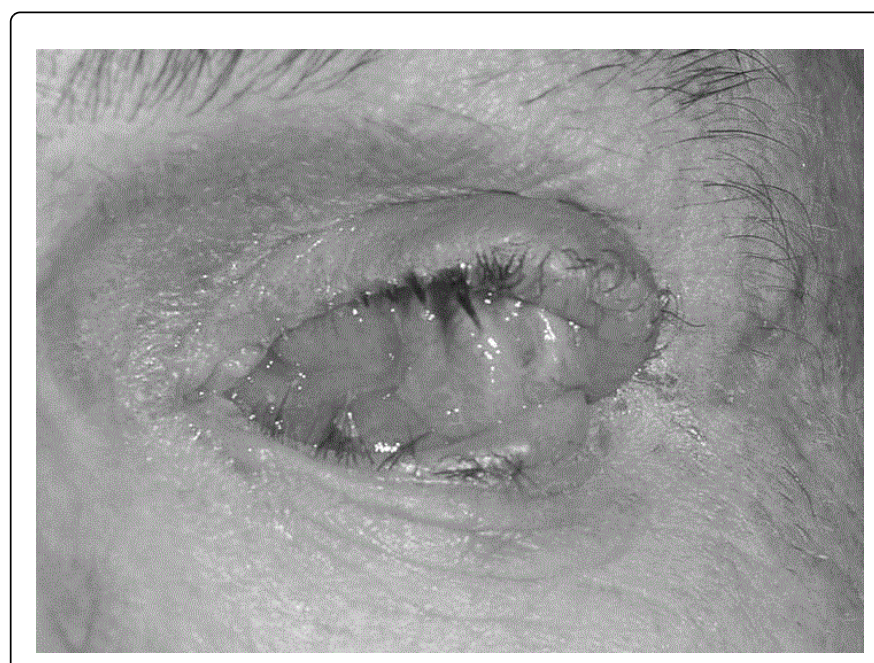

Figure 1: Contracted socket 
Page 2 of 6

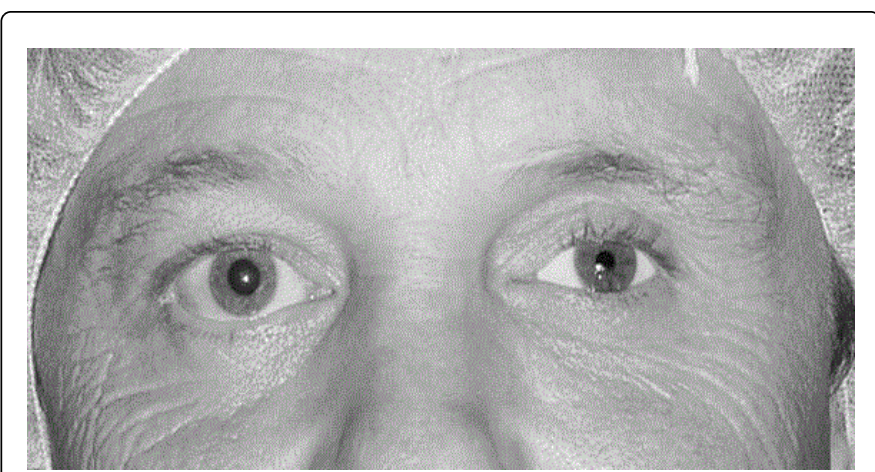

Figure 2: Mild socket contraction

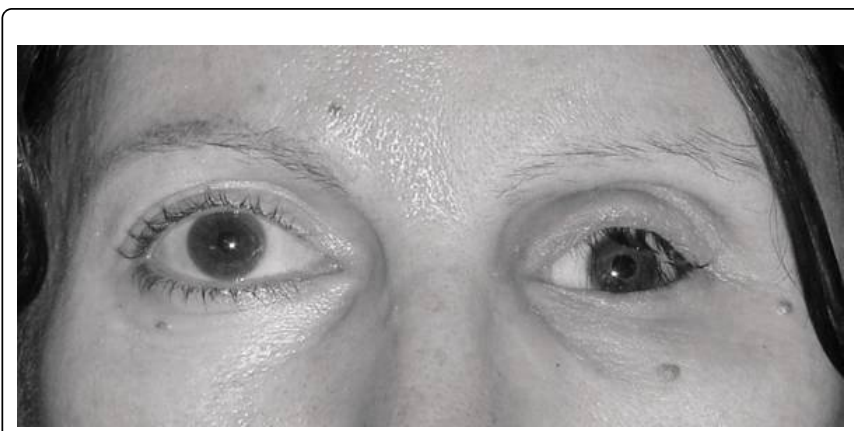

Figure 3: Moderete socket contraction

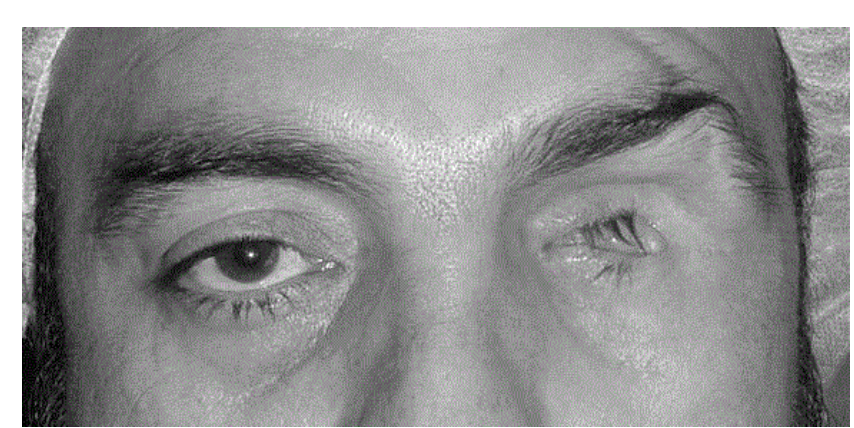

Figure 4: Severe socket contraction

In this study we aim to present our 17-year experience with patients having contracted sockets. Our series of 188 cases is one of the largest in the literature to evaluate demographic features of patients with contracted socket, additional pathologies accompanying contraction, management, and cosmetic results.

\section{Methods}

One hundred and eighty eight eyes of 188 patients with contracted sockets referred to our oculoplastic department between October 1993 and October 2010 were retrospectively analyzed. 4 surgeons performed the surgeries (DS,SK,MA,IBB). Degree of contraction was classified as mild, moderate, and severe (Table 1). Reasons for eye removal, type of initial surgery, presence of an implant, time of onset of contraction were recorded. Time of onset of contraction was considered as the time interval between the pimary surgery and the time that the patient was not able to fit the ocular prosthesis. All eyes underwent detailed oculoplastic examination. Additional pathologies accompanying contraction were detected. Surgeries performed for the contracted socket and for additional pathologies were recorded. Final status was classified as good, acceptable and poor (Table 2). Tenets of Helsinki were followed in the study and all patients gave informed consent.

The categorized data were analyzed with the chi-square test. A probability level of $<0.05$ was considered statistically significant.

\begin{tabular}{|l|l|}
\hline Mild & $\begin{array}{l}\text { Scarring or shortening of usually one fornix, mild contraction of the } \\
\text { conjunctival surface, patient can still wear an artificial eye }\end{array}$ \\
\hline Moderate & $\begin{array}{l}\text { Shortening of both fornices Some contraction in the central socket } \\
\text { Patient can wear an artificial eye with difficulty or not at all }\end{array}$ \\
\hline Severe & $\begin{array}{l}\text { Total or near total contraction of the socket. Fornices usually } \\
\text { indiscernible. Patient can not wear an artificial eye }\end{array}$ \\
\hline
\end{tabular}

Table 1: Grading of socket contraction

\begin{tabular}{|l|l|}
\hline Good & $\begin{array}{l}\text { Adequate fornices, mild or no conjunctival surface contraction, } \\
\text { patient can easily wear the prosthesis. }\end{array}$ \\
\hline Acceptable & $\begin{array}{l}\text { Some residual shortening of fornices and contraction of the } \\
\text { conjunctival surface that allows the patient to wear the } \\
\text { prosthesis, usually with some difficulty. }\end{array}$ \\
\hline Poor & $\begin{array}{l}\text { Shortening of fornices and contraction of the conjunctival } \\
\text { surface. Patient cannot wear the prosthesis. }\end{array}$ \\
\hline
\end{tabular}

Table 2: Grading of final status

\section{Results}

There were 101 (53.72\%) male and 87 (46.28\%) female patients, with an age range between 1 and 78 years (mean 35.46 years). Mean follow-up was $45.6 \pm 22.34$ months (range 5-120 months). Trauma was the reason for eye removal in $80(42.55 \%)$ patients (Table 3). Enucleation performed in $146(77.66 \%)$ patients was the most common initial surgery (Table 4). An implant was absent or extruded in $143(76.06 \%)$ patients (Table 5). Time of onset of contraction was longer than 5 years in $56(29.79 \%)$ patients (range 6 months- 53 years) (Table 6). Moderate or severe contraction was recorded in 134 (71.28\%) patients (Table 7). One hundred and fifty one $(80.32 \%)$ patients had additional pathologies and required additional interventions. Most common additional pathology was cosmetically significant volume deficit (Figure 5 and Table 8). Totally 159 interventions for additional pathologies were performed. 92 (57.86\%) were for volume deficit which was overcome by secondary implantation, implant replacement or implant revision. Totally 229 procedures were performed for socket surface expansion (Table 9) and $30.32 \%$ of patients required more than one surgery (Table 10). At the final visit, $138(73.4 \%)$ patients had good or acceptable results (Table 11).

In statistical analysis, severe contraction $(\mathrm{p}=0.02)$ and onset of contraction during the first year after primary surgery $(\mathrm{p}=0.03)$ were found to be significantly correlated with poor outcome. 
Citation: Serin D, Karslioglu S, Akbaba M, Buttanri IB, Fazil K (2014) Clinical Evaluation of 188 Patients with Contracted Socket. Surgery Curr Res 4: 203. doi:10.4172/2161-1076.1000203

Page 3 of 6

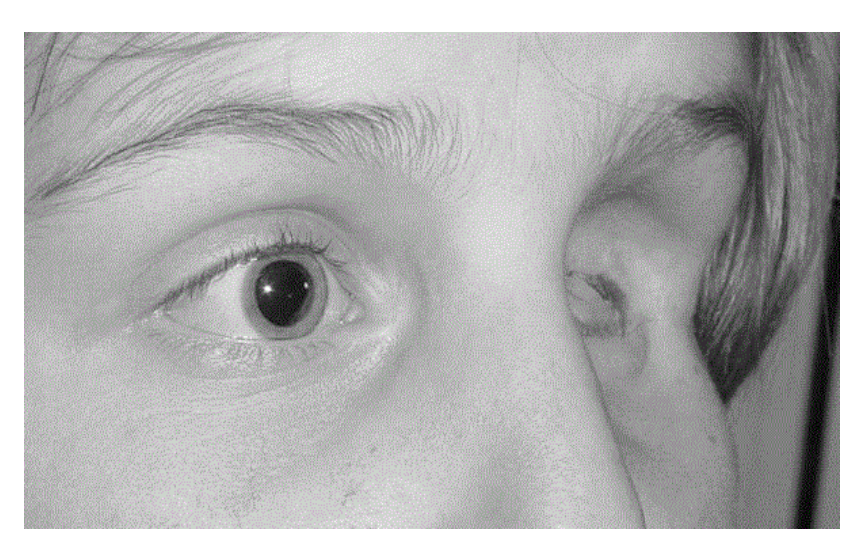

Figure 5: A patient with volume Deficit

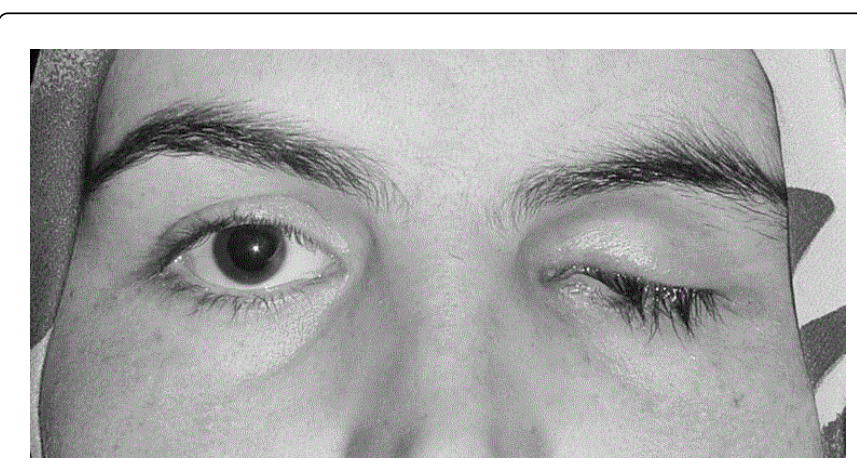

Figure 6: A patient with good outcome (Preoperative)

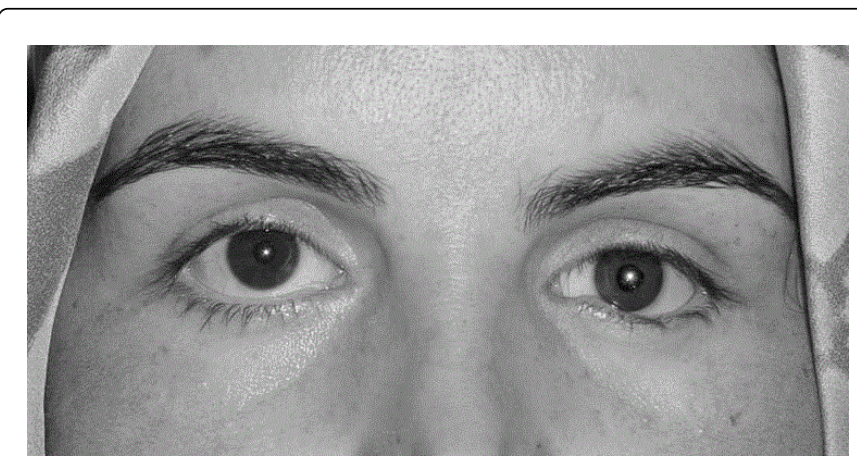

Figure 7: A patient with good outcome (Postopertive)

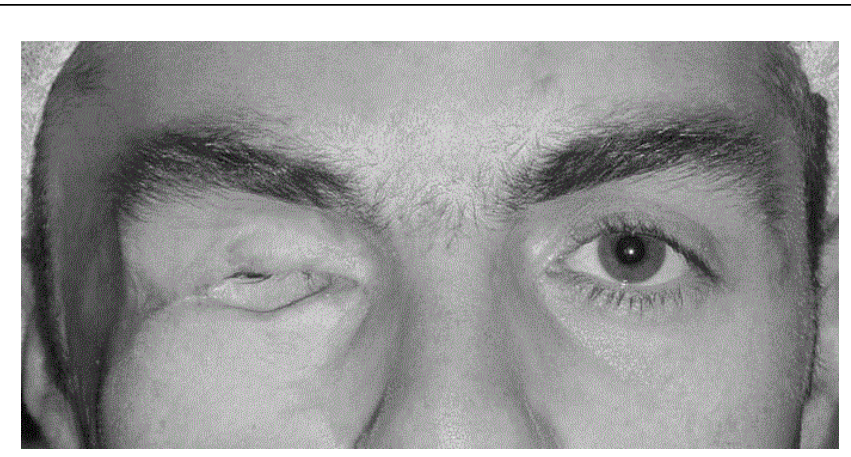

Figure 8: Even though wearing an artificial eye eventually becomes possible in the majority of cases, it is still hard for some patients even after a series of reconstructive interventions (preoperative, left)

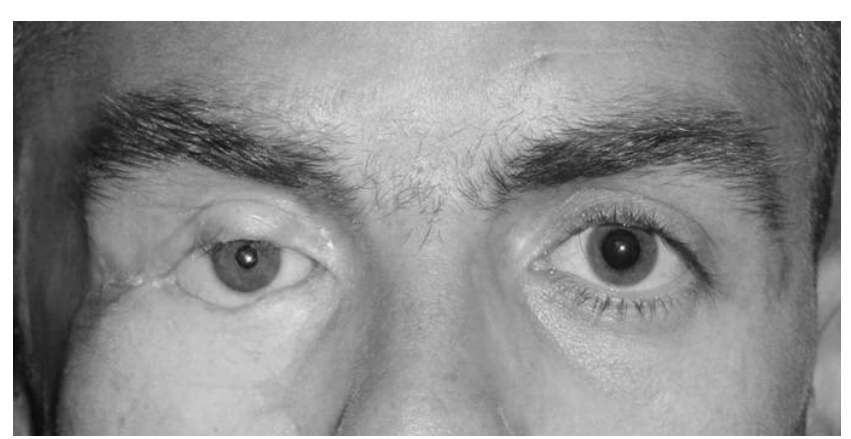

Figure 9: Even though wearing an artificial eye eventually becomes possible in the majority of cases, it is still hard for some patients even after a series of reconstructive interventions (postoperive, right)

\begin{tabular}{|l|l|l|}
\hline Etiology & Number of patients & $\%$ \\
\hline Trauma & 80 & 42.55 \\
\hline Tumor & 31 & 16.49 \\
\hline Infection & 19 & 10.11 \\
\hline Ocular & 12 & 6.38 \\
\hline Unknown & 46 & 24.47 \\
\hline Total & 188 & 100 \\
\hline
\end{tabular}

Table 3: Reasons for eye removal

\begin{tabular}{|l|l|l|}
\hline Initial surgery & Number of patients & $\%$ \\
\hline Enucleation & 146 & 77.66 \\
\hline Evisceration & 14 & 7.45 \\
\hline No surgery (Phtisis) & 16 & 8.51 \\
\hline
\end{tabular}


Citation: Serin D, Karslioglu S, Akbaba M, Buttanri IB, Fazil K (2014) Clinical Evaluation of 188 Patients with Contracted Socket. Surgery Curr

Page 4 of 6

\begin{tabular}{|l|l|l|}
\hline Unknown & 12 & 6.38 \\
\hline
\end{tabular}

Table 4: Type of initial surgery

\begin{tabular}{|l|l|l|}
\hline Implant & Number of patients & $\%$ \\
\hline Absent & 143 & 76.06 \\
\hline Present & 35 & 18.62 \\
\hline Extruded & 10 & 5.32 \\
\hline Total & 188 & 100 \\
\hline
\end{tabular}

Table 5: Presence of an implant

\begin{tabular}{|l|l|l|}
\hline Time of onset & Number of patients & $\%$ \\
\hline$<1$ year & 48 & 25.53 \\
\hline $1-5$ years & 24 & 12.77 \\
\hline $5-10$ year & 28 & 14.89 \\
\hline$>10$ years & 28 & 14.89 \\
\hline Unknown & 60 & 31.92 \\
\hline Total & 188 & 100 \\
\hline
\end{tabular}

Table 6: Time of onset of contraction

\begin{tabular}{|l|l|l|}
\hline Degree of contraction & Number of patients & $\%$ \\
\hline Mild & 54 & 28.72 \\
\hline Moderate & 115 & 61.37 \\
\hline Severe & 19 & 10.11 \\
\hline Total & 188 & 100 \\
\hline
\end{tabular}

Table 7: Degree of contraction

\begin{tabular}{|l|l|l|}
\hline Additional pathologies & Number of patients & $\%$ \\
\hline Volume deficit (cosmetically significant) & 122 & 64.89 \\
\hline Entropion & 16 & 8.51 \\
\hline Contour deformity & 16 & 8.51 \\
\hline Ptosis & 14 & 7.45 \\
\hline Lower lid laxity & 13 & 6.91 \\
\hline Symblepharon & 9 & 4.79 \\
\hline Ectropion & 9 & 4.79 \\
\hline Lid defect & 5 & 2.66 \\
\hline Orbital flor fracture & 5 & 2.66 \\
\hline Upper lid retraction & 5 & 2.66 \\
\hline Conjunctival granuloma & 2 & 1.06 \\
\hline Traumatic telecanthus & 2 & 1.06 \\
\hline
\end{tabular}

\begin{tabular}{|l|l|l|}
\hline Orbital deformity & 2 & 1.06 \\
\hline Lower lid retraction & 2 & 1.06 \\
\hline
\end{tabular}

Table 8: Additional pathologies accompanying contraction

\begin{tabular}{|l|l|l|}
\hline Procedure & Number of patients & $\%$ \\
\hline Mucous membrane graft & 114 & 49.78 \\
\hline Dermis-fat graft & 19 & 8.30 \\
\hline Skin graft & 8 & 3.49 \\
\hline Hard palata graft & 11 & 4.81 \\
\hline Fornix sutures & 24 & 10.48 \\
\hline Other & 53 & 23.14 \\
\hline Total & 229 & 100 \\
\hline
\end{tabular}

Table 9: Procedures for socket surface expansion (primary interventions)

\begin{tabular}{|l|l|l|}
\hline Number of interventions & Number of patients & $\%$ \\
\hline 1 & 85 & 45.21 \\
\hline 2 & 37 & 19.68 \\
\hline 3 & 12 & 6.38 \\
\hline 4 & 6 & 3.19 \\
\hline 5 & 2 & 1.06 \\
\hline None & 46 & 24.47 \\
\hline Total & 188 & 100 \\
\hline
\end{tabular}

Table 10: Number of interventions for socket contraction

\begin{tabular}{|l|l|l|}
\hline Final status & Number of patients & $\%$ \\
\hline Good & 41 & 21.81 \\
\hline Acceptable & 97 & 51.59 \\
\hline Poor & 14 & 7.45 \\
\hline Refused treatment & 36 & 19.15 \\
\hline Total & 188 & 100 \\
\hline
\end{tabular}

Table 11: Final Status of the patients

\section{Discussion}

Socket contraction is one of the main problems following eye removal $[1,8]$. Contraction is a progressive process that reduces socket volume $[9,10]$. It makes the patient unable to keep the ocular prosthesis in the socket. Adequate conjunctival surface and deep fornices are crucial in supporting the prosthesis. Management of contracted socket is challenging. As oculoplastic surgeons, our aim is to achieve good cosmetic results by forming a socket with adequate fornices and conjunctival surface and correction of volume deficit and 
Page 5 of 6

additional lid pathologies such as eyelid laxity, ptosis, entropion, and ectropion. In this study, we present our 17-year experience with patients having contracted sockets.

In our series, there were many etiologies for eye loss and trauma was the most common factor $(42.55 \%)$. Etiology of eye removal is differing from area to area and from country to country. In Hirako's study [11], traumatic cause of eye removal was noted in $40 \%$ of the patients. Trauma may play a role in contracture by causing tissue loss, promoting inflammation, or disturbing the vascular supply of the socket. And also financial and education level factors affect largely on the degree of contraction, as poor uneducated countries have more contraction of the sockets than others

Contraction may occur after enucleation, evisceration or phtisis. Enucleation was the primary surgery in $77.66 \%$ of our patients with contracted sockets. Enucleation itself is reported to be a possible cause for contraction [1]. Intraorbital structures are disrupted more in enucleation surgery than in evisceration; and this may play a role in contraction. Two problems have to be addressed after enucleation. First problem is volume loss and the second problem is shortening of the conjunctiva. Cosmetically significant volume loss was the most common additional pathology in our study group. In $76.06 \%$ of our patients, an implant was not present and in anophthalmic sockets, especially in those without implants, it is reported that myofibroblasts may lead to progressive contraction and the degree of contraction of the socket affected largely by the timing for eye ball implantation [9]. $92(57.86 \%)$ of additional interventions in our series were performed for volume deficit. We overcame volume deficit by secondary implantation, implant replacement, or implant revision. Reconstruction must begin at the time of eye removal. Except for some malignancy cases, primary implant placement after enucleation and evisceration must be considered in all cases, even in patients with endophthalmitis to reduce the need for delayed secondary implantations [12,13]. Implanting a sizeable orbital implant, inserting a conformer into the socket during surgery, and fitting the patient with an adequate prosthesis subsequently are essential in the rehabilitation of the anophthalmic patient.

Moderate or severe contraction was recorded in 134 (71.28\%) patients. $30.32 \%$ of patients required more than one surgery for socket surface expansion. Mucous membrane grafting is well-known technique and also was the most commonly performed procedure for socket surface expansion in our series [14]. We preferred lip and buccal mucosa. If volume deficit with contraction persisted after implantation, we performed dermis-fat grafting. Dermis-fat grafts were taken from abdominal or gluteal region. In only dry sockets, we prefered dry skin grafts. Dry skin grafts may cause some complications in wet sockets [6]. Hard-palate grafts were used for reconstruction of posterior lamella and lids. Fornix sutures were used for reconstruction of fornices in mild cases. Temporal muscle transpositions flaps were used in irradiated, avascular sockets for increasing the vascular supply. We achieved acceptable results with these procedures. Some recent studies report that amniotic membrane grafting gave cosmetically and functionally acceptable results, comparable to those of mucous membrane grafting, with a low rate of complications, and without discomfort of donor sites in cases of mild to moderate grades of contracted sockets $[15,16]$. Amniotic membrane is known to promote conjunctival epithelial cell migration over the graft, and to inhibit inflammation and fibrosis [17,18]. Presence of some healthy conjunctival epithelial cells in the socket is essential for amniotic membrane grafting [15]. We used amniotic membrane grafts only if the patients did not let us take an oral mucosal graft and in only mild to moderate cases. Further studies that compare the outcomes of all these procedures used for socket surface expansion with larger numbers of patients are required to comment on the superiority, if any, of these alternative methods over each other.

Additional pathologies may also accompany contraction in anophthalmia and these pathologies must also be managed in order to be able to keep a prosthesis in the socket and hence to increase cosmetic satisfaction. Eyelid pathologies were the second most encountered problem following volume deficit in this group of patients. Totally, 159 interventions for additional pathologies were performed. Volume deficit should be corrected before any lid surgery [1]. After management of volume deficit, we performed surgeries for socket surface expansion, then we performed surgeries for lid pathalogies which prevented fitting of the prosthesis. After fitting the ocular prosthesis, we performed lid surgeries to achieve better cosmetic results.

Good or acceptable outcome with conjunctival surface and fornices that allowed the artificial eye to be worn was achieved in $73.40 \%$ of the patients (Figures 6 and 7). Thirty six patients (\%19.15) with contracted sockets refused treatment. In only $7.45 \%$ of the operated eyes, the socket remained insufficient. Severe contraction $(\mathrm{p}=0.02)$ and onset of contraction during the first year after primary surgery $(\mathrm{p}=0.03)$ were significantly correlated with poor outcome. Rapid onset suggests a highly active progressive process which is expected to poorly respond to treatment. Similarly, it is reasonable to find that the outcomes are poor in severely contracted sockets because the conjunctival surface is insufficient, there are usually more than one accompanying additional pathologies and therefore more aggressive surgery is performed to rehabilitate these sockets and the results are more unpredictable.

In conclusion, contracted socket remains to be a challenging entity of oculoplastic surgery. It may develop at any time following removal of the eye. Additional pathologies frequently accompany the contracted socket. Even though wearing an artificial eye eventually becomes possible in the majority of cases, it is still hard for some patients even after a series of reconstructive interventions [Figure 8 and 9].

\section{References}

1. Tawfik HA, Raslan AO, Talib N (2009) Surgical management of acquired socket contracture. Curr Opin Ophthalmol 20: 406-411.

2. Silverstone PJ, Beyer-Machule CK, Schaefer DP, Della Rocca RC (1987) Treatment of anophthalmos and socket reconstruction, Ophthalmic Plastic Reconstructive Surgery: St. Louis: CV Mosby.

3. Putterman AM, Karesh JW (1988) A surgical technique for the successful and stable reconstruction of the totally contracted ocular socket. Ophthalmic Surg 19: 193-201.

4. Schaefer D (197) Evaluation and management of the anophthalmic socket and socket contracture. Smith's ophthalmic plastic and reonstructive surgery. (2ndedn). St. Louis: Mosby.

5. Migliori ME (1996) Evaluation and management of the anophthalmic socket, Principles and Practice of Ophthalmic Plastic Reconstructive Surgery. Philadelphia: WB Saunders.

6. Quaranta-Leoni FM (2008) Treatment of the anophthalmic socket. Curr Opin Ophthalmol 19: 422-427.

7. Colin JRO (2006) Enucleation, evisceration and, and socket surgery, A manual of systematic eyelid surgery. (3rd edn). London: ElsevierHeinemann. 
Citation: Serin D, Karslioglu S, Akbaba M, Buttanri IB, Fazil K (2014) Clinical Evaluation of 188 Patients with Contracted Socket. Surgery Curr Res 4: 203. doi:10.4172/2161-1076.1000203

Page 6 of 6

8. Abood MH, Weyes MM (2006) Post-traumatic reconstruction of the enucleated contracted eye socket: a comparative study. J Craniofac Surg 17: 224-230.

9. Papel ID, Frodel J, Holt R (2002) Facial Plastic and Reconstruction Surgery. (2ndedn). New York: Thieme Medical Publishers.

10. Fox SA (1970) Socket repairs. (4thedn). Ophthalmic Plastic Surgery.

11. Yanaga H, Mori S (2001) Eyelids and eye socket reconstruction using the expanded forehead flap and scapha composite grafting. Plast Reconstr Surg 108: 8-16.

12. Ozgur OR, Akcay L, Dogan OK (2007) Primary implant placement with eviceration in patients with endophthalmitis. Am J Ophthalmol 143: 902-904.

13. Tawfik HA, Budin H (2007) Evisceration with primary implant placement in patients with endophthalmitis. Ophthalmology 114: 1100-1103.
14. Mai C, Bertelmann E (2013) Oral mucosal grafts: old technique in new light. Ophthalmic Res 50: 91-98.

15. Bajaj MS, Pushker N, Singh KK, Chandra M, Ghose S (2006) Evaluation of amniotic membrane grafting in the reconstruction of contracted socket. Ophthal Plast Reconstr Surg 22: 116-120.

16. Kumar S, Sugandhi P, Arora R, Pandey PK (2006) Amniotic membrane transplantation versus mucous membrane grafting in anophthalmic contracted socket. Orbit 25: 195-203.

17. Tseng SC, Di Pascuale MA, Liu DT, Gao YY, Baradaran-Rafii A (2005) Intraoperative mitomycin $\mathrm{C}$ and amniotic membrane transplantation for fornix reconstruction in severe cicatricial ocular surface diseases. Ophthalmology 112: 896-903.

18. Klein M, Menneking H, Bier J (2000) Reconstruction of the contracted ocular socket with free full-thickness mucosa graft. Int J Oral Maxillofac Surg 29: 96-98. 